\title{
Neuzeitliche Kolonialismen: Das Kolonialreich Spanien. Der Aufstieg des spanischen Kolonialreiches an der Wende zur Frühen Neuzeit
}

\author{
Lisa-Marie Gabriel \\ Kerngebiet: Neuzeit \\ eingereicht bei: ao. Univ.-Prof. Dr. Heinz Noflatscher \\ eingereicht im Semester: SS 2014 \\ Rubrik: SE-Arbeit
}

\begin{abstract}
Early modern colonialism: The Spanish Empire. About its rise at the turn of the Early modern period

The following seminar-paper deals with early modern colonialism by the example of the Spanish Empire. How and why was the formerly small kingdom Castile-Aragón successful in conquering the so-called 'new world' and as a result in establishing one of the largest empires of global extent in world history from the $15^{\text {th }}$ to $16^{\text {th }}$ century? In this context, the paper analyses the conditions on the Iberian Peninsula at that time as well as the backgrounds of the overseas-conquest, including the impact on the indigenous population, to clarify the question of how the Spanish colonialism was designed.
\end{abstract}

\section{Einleitung}

Wollte man die Frühe Neuzeit charakterisieren, wäre die ,Entdeckung der Welt', wie es so schön heißt, sicher ein wesentlicher Indikator. Diese recht optimistisch anmutende Formulierung täuscht allerdings nur kurz darüber hinweg, dass die Entdeckung der Welt nicht nur die Erschließung neuer Gebiete und den Kontakt mit anderen Kulturen zur Folge hatte, sondern im Wesentlichen die europäische Expansion, also den Aufstieg Europas durch die Landnahme fremder Gebiete und die Ausbeutung fremder Ethnien - kurz: den frühneuzeitlichen Kolonialismus - begründete. Ein Faktor, der den Aufstieg 
und Fall ganzer Reiche zur Folge hatte und die Welt im wahrsten Sinne neu ordnete. So auch im Falle des späteren Spaniens. Bedingt durch seine Expansion im Spiegel einer von Abenteuerlust und Entdeckerdrang geprägten Epoche gelang dem in seinen Anfängen noch verhältnismäßig kleinen Herrschaftsbereich an der westlichen Peripherie des mittelalterlichen Europa der Aufstieg zur führenden Kolonialmacht der Frühen Neuzeit. Spanien avancierte durch den frühneuzeitlichen Kolonialismus, den es entscheidend mitgetragen hatte, nicht nur zur neuen Großmacht Europas, sondern begründete im gleichen Zuge auch ein knapp vier Jahrhunderte überdauerndes Weltreich.

Dieses böte zweifelsohne zahllose Möglichkeiten zur Untersuchung, doch sind es gerade die Anfänge des europäischen Ausgreifens auf damals zum Teil noch unbekannte Teile der Welt und die wesentliche Rolle der iberischen Reiche jener Zeit, die im hier vorliegenden Arbeitskontext besonders interessieren. Denn wie kam es - mit Blick auf andere etablierte (Groß-)Mächte, wie etwa England, das Heilige Römische Reich oder auch die italienischen Stadtstaaten - zu diesem schier kometenhaften Aufstieg eines seinerzeit noch gar nicht existenten Spaniens? An welche Voraussetzungen knüpfte sich der Aufstieg zur führenden Kolonialmacht der Frühen Neuzeit? Wie ging die Entdeckung und Landnahme vonstatten? Welche Ziele verfolgte der spanische Kolonialismus, und wie konnte noch im 16. Jahrhundert ein Kolonialreich in Übersee etabliert werden, als weite Teile des neu entdeckten Kontinentes noch weiße Flecken auf den Landkarten darstellten? Diese Fragen gilt es im Zuge der nachfolgenden Untersuchung anhand der einschlägigen Literaturrecherche und unter Bezugnahme auf zeitgenössische Quellen zu beantworten.

Anzunehmen ist, dass sich am Übergang vom Mittelalter zur Frühen Neuzeit insbesondere auf der Pyrenäenhalbinsel ganz wesentliche Entwicklungen für die europäische Expansion vollzogen haben, da es ausgerechnet den dort ansässigen Kleinmächten gelungen war, ihren sich seinerzeit erst formierenden Machtbereich weit über die Grenzen der damals bekannten Welt hinaus zu erweitern. Zu überprüfen ist in diesem Zusammenhang, ob die Voraussetzungen für einen Aufstieg der iberischen Reiche möglicherweise schon länger günstig waren oder ob hier eher zufällig Faktoren aufeinandertrafen, die ein Expandieren nach Übersee begünstigten. Auch könnte überlegt werden, ob im Gegensatz zu den Expansionstendenzen im Europa des 15. und 16. Jahrhunderts zeitgleich Anzeichen für einen prinzipiellen kulturellen Niedergang in der Neuen Welt festzumachen waren. Oder aber, ob der spanische Kolonialismus schlicht von entsprechend, erfolgreicher', das heißt gewaltbereiter Planung und Ausführung begleitet war. Hypothesen, die es im Verlaufe dieser Arbeit zu klären gilt.

Ein erster Teil der Arbeit widmet sich dabei zunächst der Erläuterung wichtiger Kernbegriffe rund um das Themenfeld ,Kolonialismus', um die Grenzen des eigentlichen Untersuchungsgegenstandes abzustecken. Darauf folgt ein einführendes Kapitel in Geschichte und Grundzüge des spanischen Kolonialreiches, von den ersten Ansätzen kolonialer Herrschaft auf der Iberischen Halbinsel bis zum Ausgreifen des späteren Spaniens auf die Neue Welt seit dem 15. Jahrhundert. Anschließend widmet sich ein drit- 
ter größerer Abschnitt dem Schwerpunkt dieser Arbeit: Jenem historischen Moment, das den Aufstieg und die Etablierung Spaniens zur (außer-)europäischen Großmacht am Übergang vom Mittelalter zur Frühen Neuzeit markiert. Hier wird nicht nur auf die Voraussetzungen für die spanische Expansion, sondern vor allem auch auf den Aspekt der Landnahme in Übersee - sowohl aus spanischer als auch aus überseeischer Warte betrachtet - eingegangen. Den Abschluss bildet schließlich die Frage danach, wie der spanische Kolonialismus insgesamt beschaffen war und wie dieser letztlich auch zu bewerten ist.

Was den Literatur- und Forschungsstand anbelangt, so sind die Umstände und Entwicklungen des spanischen Kolonialreiches umfassend erforscht. Oder, um bereits einleitend Eberhard Schmitt, Herausgeber der Reihe „Dokumente zur Geschichte der europäischen Expansion“, zu zitieren: „Die Literatur zum Stoff ist naturgemäß außerordentlich umfangreich und wächst schnell weiter an". So auch im hier vorliegenden Falle, wobei zahlreiche Werke aus den 1980er- und 1990er-Jahren stammen. Zum allgemeinen Überblick wurden die Online-Version der „Enzyklopädie der Neuzeit” sowie diverse Ausgaben zur Geschichte Spaniens konsultiert. Etwa Klaus Herbers "Geschichte Spaniens im Mittelalter", erschienen 2006, oder Walther L. Berneckers "Spanische Geschichte" mit Fokus auf Neuzeit und Moderne aus dem Jahr 1999. Für die begriffliche Annäherung war vor allem Jürgen Osterhammels und Jan C. Jansens bereits in siebter Auflage in der C. H. Beck Reihe Wissen erschienener Band "Kolonialismus" sehr hilfreich. Selbiges gilt für Josep Fraderas 2008 publizierten Aufsatz „Spanien - Ursprung des modernen Kolonialismus", der einen umfassenden Überblick zum spanischen Kolonialreich bietet und als exemplarisches Beispiel „wissenschaftlicher Selbstreflexion“2 gilt.

\section{Zum Begriffsfeld ,Kolonialismus`}

Zum Themenfeld,Kolonialismus' seien vorab drei Dinge festgestellt: Erstens beschreibt dieser gemeinhin negativ konnotierte Begriff, der mit Aspekten wie "Fremdbestimmung, Rassismus, gewaltsame[r] Usurpation und illegitime[r] Aneignung"3 verbunden ist, zunächst schlicht eine Herrschaftsform, die ganz unterschiedliche Ausprägungen haben kann. ${ }^{4}$ Zweitens geht der Begriff des Kolonialismus oft mit verwandten Termini wie, Imperialismus' oder,Expansion' konform, weshalb auf diese nachfolgend ebenfalls kurz eingegangen wird. Drittens ist der frühneuzeitliche Kolonialismus von dem des späten 19. und frühen 20. Jahrhunderts zu unterscheiden, ${ }^{5}$ wenngleich sich die Ge-

1 Eberhard Schmitt, Vorwort, in: Die mittelalterlichen Ursprünge der europäischen Expansion (Dokumente zur Geschichte der europäischen Expansion 1), München 1986, S. V-VIII, hier S. VII.

2 Michael Weidert, Rezension zu: Ein Platz an der Sonne, in: Sehepunkte. Rezensionsjournal für die Geschichtswissenschaften, 8 (2008), Nr. 11., [http://www.sehepunkte.de/2008/11/14373.html], eingesehen 16.6.2015.

3 Jürgen Osterhammel/Jan C. Jansen, Kolonialismus. Geschichte, Formen, Folgen (C. H. Beck Reihe Wissen), München $2012^{7}$, S. 7.

4 Osterhammel/Jansen, Kolonialismus, S. 7. Die Autoren bieten in ihrem Band rund um das titelgebende Themenfeld Vorschläge zu Definition und Klassifikation. Ebd., S. 7-28.

5 Helmut Bley, Kolonialismus, in: Bley, Helmut/König, Hans-Joachim/Ahuja, Ravi/Nolte, Hans-Heinrich, Enzyklopädie der Neuzeit, [http://referenceworks.brillonline.com/entries/enzyklopaedie-der-neuzeit/kolonialismus-a2159000], eingesehen 12.4.2015. (Die Online-Version der Enzyklopädie der Neuzeit findet sich in den Fußnoten nachfolgend unter der Sigle „ENZ Online“ abgekürzt.) 
schichte mehrerer ehemaliger europäischer Kolonialmächte jeweils über beide Zeithorizonte erstreckt. Der Unterschied liegt dabei in den zum Teil gegenläufigen Entwicklungstendenzen der beiden Phasen begründet: Während sich die europäischen Kolonialmächte und ihre (überseeischen) Besitzungen bis ins 18. Jahrhundert hinein überhaupt erst formierten, ist die zweite Phase durch eine unbestreitbare Hegemonialstellung der europäischen Länder einerseits, gleichzeitig aber durch umfassende Umwälzungsprozesse in Form von Dekolonisations- und Unabhängigkeitsbestrebungen in den Kolonien andererseits gekennzeichnet. Oder anders ausgedrückt: Die ersten Jahrhunderte des frühneuzeitlichen Kolonialismus schufen die Voraussetzungen für jene Staatenwelt, die sich in der zweiten Phase schließlich herausbildete. ${ }^{6}$

Um also auf die Begrifflichkeiten zurückzukommen: Dass eine Definition der Kernbegriffe ,Kolonialismus', Kolonisation' und ,Kolonie' ebeno schwierig ist, wie eine Abgrenzung von bedeutungsähnlichem Fachvokabular, nehmen schon Jürgen Osterhammel und Jan C. Jansen angesichts ihrer Begriffsannäherung vorweg: „Kolonisation [und damit wohl auch die verwandten Begriffe, Anm.] ist mithin ein Phänomen von kolossaler Uneindeutigkeit“? Ähnliches unterstreicht der Blick in die „Enzyklopädie der Neuzeit“, wo Helmut Bley mit Bezug auf Osterhammels Definition von Kolonialismus ${ }^{8}$ konstatiert, dass gewisse Aspekte davon auch „für nicht durch europäischen Kolonialismus bedingte Überlagerungsprozesse, in nicht-europäischen Gesellschaften und in Gesellschaften innerhalb Europas"9 ${ }^{\prime \prime}$ utreffen können. Das heißt, „Eroberung und Überlagerung sind sehr alte und beständige Phänomene von Herrschaft", ${ }^{10}$ die nicht immer gleichbedeutend mit Kolonialismus sind. Dennoch sei für die hier vorliegende Arbeit auf den Verständnisvorschlag von Osterhammel/Jansen verwiesen:

„,Kolonisation' bezeichnet im Kern einen Prozeß der Landnahme, Kolonie' eine besondere Art von politisch-gesellschaftlichem Personenverband, ,Kolonialismus' ein Herrschaftsverhältnis. Das Fundament aller drei Begriffe ist die Vorstellung von der Expansion einer Gesellschaft über ihren angestammten Lebensraum hinaus." ${ }^{111}$

Interessant ist hierbei, dass sich genannte Begriffe etymologisch betrachtet jeweils auf das 16. bis 18. Jahrhundert, also die Hochzeit des europäischen Kolonialismus, zurückführen lassen. So ist das Abstraktum ,Kolonialismus', abgeleitet von ,Kolonie', das

6 Bley, Kolonialismus, ENZ Online; Wolfgang Reinhard, Geschichte der europäischen Expansion, Bd. 2, Die Neue Welt, Stuttgart-Berlin-Köln-Mainz 1985, S. 7.

7 Osterhammel/Jansen, Kolonialismus, S. 8.

$8 \quad$ Kolonialismus ist eine Herrschaftsbeziehung zwischen Kollektiven, bei welcher die fundamentalen Entscheidungen über die Lebensführung der Kolonisierten durch eine kulturell andersartige und kaum anpassungswillige Minderheit von Kolonialherren unter vorrangiger Berücksichtigung externer Interessen getroffen und tatsächlich durchgesetzt werden. Damit verbinden sich in der Neuzeit in der Regel sendungsideologische Rechtfertigungsdoktrinen, die auf der Überzeugung der Kolonialherren von ihrer eigenen kulturellen Höherwertigkeit beruhen." Ebd., S. 20.

9 Bley, Kolonialismus, ENZ Online. Bei letzterem denke man beispielsweise an das Venedig der Frühen Neuzeit, das entlang der Adriaküste ein erstes innereuropäisches Kolonialreich errichtete, oder aber an das iberische Königreich Aragón, von dem im Verlaufe dieser Arbeit noch die Rede sein wird.

10 Ebd

11 Osterhammel/Jansen, Kolonialismus, S. 8 f. 
wiederum auf das lateinische colonia („Länderei, Ansiedlung, Kolonie“12) beziehungsweise colonius („Ansiedler, Bebauer"13) oder colere („bebauen, (be)wohnen“14) zurückgeht, seit dem 16. Jahrhundert nachweisbar. ${ }^{15}$ Ebenso ,Imperialismus', abgeleitet vom lateinischen imperium, ${ }^{16}$ was so viel bedeutet wie „Bewefehlsgewalt, Reich".17 Laut Jörg Fisch "ein rechtlich mehr oder weniger genau bestimmter Begriff, dem daneben auch verschiedene nichtrechtliche Bedeutungen zukamen." ${ }^{18}$ Das heißt also, dass, Imperium' respektive, Imperialismus' per se nur schwer zu definieren sind und im Laufe der Zeit, etwa quer durch die europäische Epochengliederung, ganz unterschiedlich konnotiert waren. Dennoch darf in Annäherung an den Begriff festgehalten werden, dass er jeweils "die Tendenzen auf Machterweiterung, bis hin zur angestrebten Weltherrschaft"19 mit sich trägt. ${ }^{20}$

Als jüngster Fachausdruck im Kontext lässt sich seit dem 18. Jahrhundert schließlich auch die ,Expansion', vom lateinischen expandere, was so viel bedeutet wie "Ausweitung, Vergrößerung",21 nachweisen. ${ }^{22}$ Ein Schlagwort, das auch Osterhammel/Jansen in ihre obig angeführte Begriffserläuterung einbezogen haben, und das zumeist in seiner erweiterten Form im Sinne der,europäischen Expansion' auftritt. Beschrieben wird damit die Entdeckung der Welt durch die europäischen Mächte der Frühen Neuzeit und der damit beginnende Prozess von Herrschaftsverdichtung und Austauschbeziehungen, der Europa bis zur Mitte des 19. Jahrhunderts nicht nur eine Vormachtstellung im Weltgeschehen bescheiden, sondern einen umfassenden Strukturwandel auf allen Kontinenten zur Folge haben sollte, wie weiter oben schon angedeutet. ${ }^{23}$ Entscheidend für die Bezeichnung,europäische Expansion’ ist jedenfalls die Tatsache, „dass der Anstoß zu dieser Ausweitung von Europa ausging und dass sie durch europäische Länder in Gang gehalten wurde."24 Allen voran das frühneuzeitliche Spanien, das im Blickpunkt nachfolgender Ausführungen steht.

12 Kolonie, in: Duden online, [http://www.duden.de/rechtschreibung/Kolonie], eingesehen 14.4.2015.

13 Kolonie, in: Friedrich Kluge, Etymologisches Wörterbuch der deutschen Sprache, Berlin-New York $2011^{25}$, S. 515.

14 Kolonie, Duden online.

15 Kolonie, Kluge Etymologiewörterbuch, S. 515. Interessanterweise findet das Wort "Kolonie” Josep Fradera zufolge ausgerechnet bei den Spaniern, als „(Mit-)Begründern“ der europäischen Expansion wenn man so will, erst seit dem späten 18. Jahrhundert und nur in Bezug auf die karibischen Zuckeranbaugebiete Verwendung. Josep Fradera, Spanien - Ursprung des modernen Kolonialismus, in: Robert Aldrich (Hrsg.), Ein Platz an der Sonne. Die Geschichte der Kolonialreiche, Stuttgart 2008, S. 44-68, hier S. 53.

16 Imperium, Kluge Etymologiewörterbuch, S. 439 f.

17 Ebd., S. 439.

18 Jörg Fisch, Imperialismus, I. Einleitung - II. 3. Neuzeit, in: Otto Brunner/Werner Conze/Reinhart Koselleck (Hrsg.), Geschichtliche Grundbegriffe. Historisches Lexikon zur politisch-sozialen Sprache in Deutschland, Band 3 H-ME, Stuttgart 1982, S. 171-175, hier S. 171.

19 Ebd.

20 Detailliertere und weiterführende Informationen zu Begriff und Theorien von ,Imperialismus' finden sich ebd., S. $171-236$.

21 Expansion, Kluge Etymologiewörterbuch, S. 267.

22 Ebd.

23 Helmut Bley, Expansionen, in: Ders./Suraiya Faroqhi/Hans-Heinrich Nolte/Hans-Joachim König/Stefan Rinke (Hrsg.), EnzyklopädiederNeuzeit[http://referenceworks.brillonline.com/entries/enzyklopaedie-der-neuzeit/expansionen -a1004000], eingesehen 12.4.2015; Reinhard, Die Neue Welt, S. 7. 


\section{Das Kolonialreich Spanien}

Spricht man vom spanischen Kolonialreich, ist damit gemeinhin die Vorstellung von Spaniens Großmachtwerdung im Zuge der Frühen Neuzeit durch die Landnahme im neu entdeckten Mittel- und Südamerika verbunden. Zwar beschäftigt sich die hier vorliegende Arbeit mit ebendiesem Beispiel neuzeitlicher Kolonialismen, doch bleiben dabei oft mehrere Aspekte unbedacht:

Erstens reichen die, kolonialen Erfahrungen' Spaniens deutlich weiter zurück als bis in das späte 15. Jahrhundert. Dabei waren es nicht immer die Herrscher auf der Iberischen Halbinsel, die als Kolonialherren fungierten.

Zweitens hat sich dieses frühneuzeitliche Spanien, das aus mehreren Herrschaftsbereichen im Gebiet der Pyrenäenhalbinsel bestand, erst im Zuge des späten Mittelalters formiert. Das heißt zum einen, dass die Rede von einem König- oder Kolonialreich,Spanien' für die Anfänge des spanischen Kolonialismus, die bereits im Spätmittelalter zu suchen sind, eigentlich falsch ist. Ein Königreich Spanien existierte bis ins 16. Jahrhundert hinein nicht. Der Einfachheit halber sei diese Bezeichnung unter Vorbehalt vorerst trotzdem beibehalten, genauere Ausführungen zu den Anfängen des spanischen Kolonialreiches finden sich indes im Folgenden dargelegt. Zum anderen bedeutet dies aber auch, dass aufgrund dieses territorialen Zusammenwachsens an der Wende zur Frühen Neuzeit überhaupt erst die Weichen für den Aufstieg Spaniens zur (außer-)europäischen Großmacht sowie zur gesamteuropäischen Expansion nach Übersee gestellt wurden. Ein Punkt, dem sich ein eigenes Kapitel dieser Arbeit widmet.

Drittens und letztens scheint die so genannte spanisch-amerikanische Variante eine Sonderform innerhalb der Kolonialismusforschung darzustellen. Ein Umstand, der am Ende dieser Arbeit und unter Einbezug der hier vorgenommenen Untersuchungen betrachtet wird.

\section{Die,kolonialen` Erfahrungen der Iberischen Halbinsel}

Wie erwähnt, reichen die,kolonialen Erfahrungen' des historischen Spanien bedeutend weiter zurück als bis in das 15. Jahrhundert. Insofern können die kolonialgeschichtlichen Anfänge der Iberischen Halbinsel bis in das erste vorchristliche Jahrtausend zurückgeführt werden. So siedelten etwa die Phönizier - ein aus dem Raum der Levante stammendes antikes Handels- und Seefahrervolk, das durch die Errichtung von Handelsstützpunkten nahezu den gesamten Mittelmeerraum kolonialisierte - bereits an der spanischen Küste. Als weitere Etappen könnten auch die römische Oberherrschaft oder die Herrschaftsverlagerung des Westgotenreiches in den Raum um Toledo, im heutigen Zentralspanien, genannt werden, ebenso wie die maurische Fremdherrschaft seit dem 8. nachchristlichen Jahrhundert. ${ }^{25}$ All diesen Beispielen gemein ist dabei, dass der Raum südlich der Pyrenäen jeweils koloniales Gebiet und nicht Mutterland eige-

25 Klaus Herbers, Geschichte Spaniens im Mittelalter. Vom Westgotenreich bis zum Ende des 15. Jahrhunderts, Stuttgart 2006, S. 23-26, S. 36 f., S. 72 f. 
ner Kolonien war, wenngleich sich gerade hier auch die bereits erwähnten Definitionsschwierigkeiten zeigen. Es stellt sich nämlich die Frage, ob tatsächlich in all diesen Fällen von Kolonialismus gesprochen werden kann, oder ob es sich schlicht um die Ver- oder Überlagerung von Herrschaft handelte.

Ein entsprechender Rollenwechsel lässt sich jedenfalls erst im Zuge des europäischen Frühmittelalters feststellen: Seit etwa $711^{26}$ hatte sich die Pyrenäenhalbinsel unter dem Eindruck zweier divergierender Einflusssphären - einer islamischen und einer christlichen - zu einem vielgestaltigen Gebiet mit muslimischen, jüdischen und christlichen Traditionen formiert. Innerhalb des stark christlich dominierten mittelalterlichen Europa zunächst großteils unter islamischer Herrschaft stehend, etablierten sich seit dem 12. Jahrhundert schließlich die so genannten,Fünf Reiche ${ }^{27}$ des christlichen Spaniens in Auseinandersetzung mit den muslimischen Herrschern im Süden. Es sind dies Kastilien, Léon, Aragón, Navarra und Portugal, wobei Kastilien und Léon bereits im 13. Jahrhundert zu einem Herrschaftsgebiet verschmolzen. ${ }^{28}$ Für eine leichtere geopolitische Verortung der nachfolgend geschilderten Ereignisse finden sich zwei Karten im Anhang. Abbildung 1 zeigt die Iberische Halbinsel unter dem Eindruck der nach Norden ausgreifenden muslimischen Herrschschaft im 12. Jahrhundert. Abbildung 2 hingegen die Umkehr des Status Quo durch die zunehmende Ausdehnung der christlichen Reiche gen Süden - im Falle der Krone Aragón auch nach Osten ins Mittelmeer - im nachfolgenden 13. Jahrhundert. Letzteres war Voraussetzung für die Großmachtwerdung des späteren Kolonialreiches Spanien, dessen Geschichte im Folgenden skizziert wird.

\section{Die Genese des spanischen Kolonialreiches im Überblick}

Wie unter Punkt Zum Begriffsfeld ,Kolonialismus' erläutert, lassen sich seit der Frühen Neuzeit zwei Phasen dieses Phänomens festmachen, wobei fast alle europäischen KoIonialmächte Anteil an beiden Etappen hatten. Dies trifft nicht auf Spanien zu. Zwar war es Spanien, das in seiner spätmittelalterlichen Form als ein Initiator der europäischen Expansion fungierte ${ }^{29}$ und dadurch auch als einer der ersten Expansionsakteure noch im 16. Jahrhundert zur Großmacht aufstieg, allerdings ging das spanische Kolonialreich bereits mit den 1820er-Jahren langsam seinem Ende zu und hörte mit dem

26 Das Jahr 711 wird in der Geschichte der Iberischen Halbinsel als Zäsur beziehungsweise als Epochengrenze zwischen Antike und Mittelalter diskutiert: Es folgte das Ende des Westgotenreiches und der Aufstieg islamischer Dominanz als Gegensatz zu einer bereits etablierten christlichen Tradition. Herbers, Geschichte Spanien Mittelalter, S. 72.

27 Ein Terminus, der vom spanischen Historiker Ramón Menéndez Pidal 1950 in seinem von Herbers zitierten Werk „El imperio hispánico y los cinco reinos“ geprägt wurde. Menéndez Pidal formulierte im Zusammenhang drei Epochen der Rückeroberung Spaniens, wobei er die dritte Phase - jene der "cinco reinos”, also der „Fünf Reiche” Spaniens - mit einer ersten "nationalen“ Idee verbunden sehen wollte. Juan López Marichal, Rezension zu: El imperio hispánico y los cinco reinos, in: Nueva Revista de Filología Hispánica 5 (1951), Nr. 3, S. 338-340, hier S. 338, S. 339 f., [http://www.jstor.org/stable/40296709], eingesehen 7.7.2015.

28 Herbers, Geschichte Spanien Mittelalter, S. 178. Siehe zu letztgenanntem die Karten im Anhang: Abbildung 1 im Vergleich zu Abbildung 2 verdeutlicht das Zusammenwachsen von Kastilien-Léon vom 12. zum 13. Jahrhundert.

29 Wolfgang Reinhard, Autor des zweibändigen „Geschichte der europäischen Expansion”, stellt indessen bereits in seinem Vorwort die Entwicklungen des portugiesischen Mittelalters an die Anfänge der europäischen Expansion, in: Ders., Geschichte der europäischen Expansion, Bd. 1, Die Alte Welt bis 1818, Stuttgart 1983, S. 7. Ein Umstand, der unter dem Punkt Der Blick aufSpanien noch Thema sein wird. 
Verlust der letzten verbliebenen Kolonien 1898 endgültig auf zu existieren. ${ }^{30}$ Das heißt, das hispanoamerikanische Großreich umfasst damit zeitlich knapp vier Jahrhunderte und endete bereits vor dem Eintritt anderer europäischer Kolonialmächte in die Phase des Imperialismus im späten 19. und frühen 20. Jahrhundert. Dennoch lassen sich auch in der Geschichte des spanischen Kolonialreiches zwei große Entwicklungszüge feststellen:

Walther L. Bernecker schlägt beispielsweise eine Gliederung der spanischen Geschichte vom 15. Jahrhundert bis zur zweiten Jahrtausendwende vor, die mit dem 15. bis 18. Jahrhundert eine erste Episode umfasst. Das 15. Jahrhundert markiert dabei die "Grundlegung des Reiches","11 das 16. Jahrhundert Spaniens „Aufstieg zur Weltmacht", das 17. Jahrhundert zugleich "Hegemonie und Niedergang".33 Die Zeit vom 18. Jahrhundert bis heute ist als zweite Episode hingegen von ebenjenen Separationstendenzen bestimmt, die das europäische Spanien nicht nur zum Aktionsfeld divergierender soziopolitischer Akteure und Forderungen machten, sondern die auch zum Ende des spanischen Kolonialreiches mit beziehungsweise durch den Verlust seiner überseeischen Besitzungen führten. ${ }^{34}$

Freilich handelt es sich bei Berneckers Geschichtseinteilung in erster Linie um eine Epochengliederung innerhalb der Grenzen des heutigen EU-Staates und um keine spezifisch spanische Kolonialgeschichte. ${ }^{35}$ Dennoch deckt sich die etwas künstlich anmutende,Taktung' quer durch die Jahrhunderte durchaus mit tatsächlichen, Jahrhunderttendenzen' und findet sich ähnlich auch bei anderen Autoren, wenngleich deren spezifisch kolonialgeschichtlicher Blick eine etwas adaptierte Entwicklungsabfolge zulässt. Demnach scheint sich die Forschung - unabhängig von ihrem mehr oder minder kolonialhistorischen Blick - darüber einig, dass das 15. Jahrhundert die Voraussetzungen für jenes Weltreich schuf, auf das Spanien bereits im 16. Jahrhundert blicken konnte. Ein Aspekt, dem sich das Kapitel An der Wende zur Frühen Neuzeit: Spaniens Aufstieg zur Weltmacht im Detail widmet.

Was die nachfolgenden Jahrhunderte anbelangt, gehen die Ansichten interessanterweise etwas auseinander: Die Darstellung Bartolomé Bennassars und Bernard Vincents

30 Fradera, Moderner Kolonialismus, S. $65 \mathrm{f}$.

31 Walter L. Bernecker, Spanische Geschichte. Vom 15. Jahrhundert bis zur Gegenwart (C. H. Beck Reihe Wissen 2111), München 1999, S. 7.

32 Bernecker, Spanische Geschichte, S. 19

33 Ebd., S. 35.

34 Ebd., Inhaltsverzeichnis beziehungsweise im Detail S. 52-112. Bernecker formuliert insgesamt zehn Entwicklungslinien in seiner "Spanischen Geschichte“. Die ersten drei sind bereits genannt, die weiteren sind: „Das Zeitalter der Reformen (18. Jahrhundert)”, „Die Krise des Ancien Régime (1788-1808)“, „Die Ära der Militärputsche (1808-1875)“, „Restauration und Diktatur (1875-1930)“, „Zweite Republik und Bürgerkrieg (1931-1939)“, „Die Franco-Ära (1939-1975)“, "Monarchie und Demokratie (1975-1999)“.

35 Der Autor verweist schon einleitend selbst darauf, dass die "Geschichte des hispanoamerikanischen Kolonialreiches [...] nur dann einbezogen wurde, wenn sie für das Verständnis der Entwicklung Spaniens erforderlich war." (Bernecker, Spanische Geschichte, Vorwort). Ein Umstand, der zwar etwas irritiert, da die Geschichte Hispanoamerikas wohl ebensowenig ohne Blick auf das europäische Mutterland auskommt, wie dies umgekehrt der Fall sein dürfte, der unter Berücksichtigung von Berneckers Arbeitsintention, eine Geschichte des heutigen EU-Staates Spanien zu liefern, aber durchaus verständlich ist. Es kann also davon ausgegangen werden, dass letztlich alle der von Bernecker formulierten Entwicklungslinien Einfluss auf das gesamte Kolonialreich hatten. 
zum Wendepunkt der spanischen Kolonialgeschichte - von der Glanzzeit im 16. Jahrhundert zum Zerfall ab dem 17. Jahrhundert ${ }^{36}$ - gehen mit Berneckers Gliederung konform. Ganz im Gegensatz dazu lassen sich aus Fraderas Erläuterungen für das 17. Jahrhundert vor allem Ausbeutungs- aber auch Autonomietendenzen innerhalb der Kolonien ablesen, während erst das 18. Jahrhundert den gleichzeitigen Höhepunkt und beginnenden Niedergang markiert. Denn obwohl das Spanien des 17. Jahrhunderts - bedingt durch schwache Herrscherpersönlichkeiten ${ }^{37}$ und den Spanischen Erbfolgekrieg ${ }^{38}$ zu Beginn des Folgejahrhunderts - in Europa an Stärke verlor, entwickelte sich in Übersee ein überaus florierender Bergbau, der der spanischen Kasse Tonnen an Gold und Silber bescherte, ${ }^{39}$ sowie eine neue koloniale Gesellschaft unter dem Deckmantel einer differenzierteren Verwaltung. ${ }^{40}$

Möglicherweise mögen diese Autonomietendenzen für das Mutterland negativer Natur gewesen sein, die Macht in Hispanoamerika konnte Fradera zufolge im 17. Jahrhundert jedenfalls noch gefestigt werden. Noch im 18. Jahrhundert konnte das Spanien jener Zeit also seine größte territoriale Ausbreitung verzeichnen, wenngleich sich spätestens hier auch erste Probleme abzeichneten. ${ }^{41}$ Fradera spricht etwa vom „Aushöhlen des imperialen Regierungssystems" ${ }^{42}$ und den „ständig wachsenden Widersprüche[n] des spanischen Kolonialreiches",43 was die schon länger bestehende "tiefsitzende Unzufriedenheit im Volk"44 schürte und letztlich zu Aufständen und Bürgerkrieg führte. ${ }^{45}$ Dies spiegelt sich wiederum in der Geschichte des Mutterlandes wider: Nach Bernecker gilt die Zeit von 1788-1808 als „Krise des Ancien Régime“,46 die Episode von 1808-1875 als "Ära des Militärputsches",47 vergleichbar der Revolution von 1789 und ihrer Folgewirkungen im französischen Nachbarland. ${ }^{48}$ Mit Beginn des 19. Jahrhunderts war der Niedergang des spanischen Kolonialreiches demnach endgültig besiegelt: Ein militärischer Sieg der Separatisten über die spanische Kolonialherrschaft in den 1820er-Jahren

36 So implizieren es zumindest Werktitel und Inhaltsgliederung: Bartolomé Bennassar/Bernard Vincent, Spanien. 16. und 17. Jahrhundert. Das Goldene Zeitalter, Stuttgart 1999, Inhaltsverzeichnis beziehungsweise konkret S. 14 f., $84 \mathrm{f} ., 136 \mathrm{f}$

37 Bernecker, Spanische Geschichte, S. 35.

38 Ebd., S. 46.

39 Fradera, Moderner Kolonialismus, S. 50. Eine interessante Studie mit zahlreichen weiterführenden Informationen speziell zur spanisch-kolonialen Edelmetallgewinnung bietet Carlo M. Cipolla, Die Odyssee des spanischen Silbers. Conquistadoren, Piraten, Kaufleute, Berlin 1998.

40 Fradera, Moderner Kolonialismus, S. 47, 50, 52.

41 Zu nennen ist hier vor allem das verstärkte Aufkommen soziopolitisch fragwürdiger Ideen, die allerdings dem Kontext der Zeit durchaus entsprechen: Zum einen festigte sich die Ansicht von der Expansion als heiligem Auftrag. Das heißt, die kirchlich-missionarische Einflussnahme wurde bedeutender - vermutlich eine Begleiterscheinung der Reformation in Europa, die im katholischen Spanien wohl die Bestrebungen zur intensivierten Missionierung geschürt haben dürfte. Zum anderen kam auch die Idee der "rassischen Reinheit" auf, was in weiterer Folge zur Etablierung eines Kastenwesens beziehungsweise einer regelrechten Rassenlehre führte, um die in den Kolonien ansässigen und im Laufe der Kolonialgeschichte vermischten Ethnien möglichst voneinander abzugrenzen. Fradera, Moderner Kolonialismus, S. 51 f., 56, 58 
markierte deren formales Ende und führte zur Befreiung fast aller Kolonien, woraus die sechs unabhängigen Länder Venezuela, Kolumbien, Panama, Ecuador, Peru und Bolivien entstanden. Einzig Kuba, Puerto Rico und die Philippinen blieben weiterhin kolonialer Besitz. ${ }^{49}$

Im Zuge mehrerer Unabhängigkeitskriege lösten sich aber schließlich auch diese bis 1898 aus der kolonialen Oberherrschaft und läuteten das faktische Ende des spanischen Kolonialreiches ein. An dessen Stelle traten nun die USA, die mit ihrem Eintritt auf die Bühne des Imperialismus bereits zu Beginn des 19. Jahrhunderts ihr Interesse an karibischen Besitzungen bekundet hatten, die sie in Auseinandersetzung mit Spanien letztlich auch gewannen. ${ }^{50}$

\section{An der Wende zur Frühen Neuzeit: Spaniens Aufstieg zur Weltmacht}

Der Aufstieg Spaniens zur neuen Großmacht des frühneuzeitlichen Europa ist im Wesentlichen von zwei Faktoren bestimmt: Zum einen von den seit dem Spätmittelalter vorherrschenden Entwicklungstendenzen, die im 15. Jahrhundert mehr oder minder zufällig im iberischen Raum derart zusammenspielten, dass dort die nötigen Voraussetzungen für eine Einflusserweiterung der ansässigen Mächte gegeben waren. Zum anderen von der sukzessiven Inbesitznahme der neu entdeckten Gebiete in Übersee. Faktoren, denen sich dieses letzte Kapitel widmet.

\section{Die Voraussetzungen im 15. Jahrhundert}

Wie im historischen Überblick zur Entwicklung des spanischen Kolonialreiches im vorhergehenden Kapitel dargelegt, gilt das 15. Jahrhundert gemeinhin als Jahrhundert der Grundsteinlegung für die spanische respektive europäische Expansion und den damit einhergehenden Aufstieg der iberischen Mächte. So kulminierten im Spanien jener Zeit mehrere Ereignisse, Tendenzen und Entwicklungen fruchtbringenden Charakters, die Günter Vogler zufolge auf vier Säulen beruhten:

„Erstens wurde mit der Personalunion der Kronen Kastilliens und Aragons das Fundament für einen zentralistischen Staat gelegt. Zweitens wurde mit der Vollendung der Reconquista die iberische [sic] Halbinsel von fremder Herrschaft befreit. Drittens wurde mit der überseeischen Expansion das spanische Weltreich begründet. Viertens wurde die strikte Katholizität des Landes gesichert." ${ }^{11}$

Was Vogler hier als vier scheinbar aufeinander aufbauende Entwicklungsstufen formuliert, ist in Wahrheit ein komplexes Konstrukt sich gegenseitig beeinflussender Faktoren, die in Kombination schließlich zur spanischen Expansion und zum Weltmachtdasein führten. So waren die genannte Personalunion, geschlossen 1469, sowie die 1492

\footnotetext{
49 Fradera, Moderner Kolonialismus, S. 62.

50 Ebd., S. 65 f.

51 Günter Vogler, Europas Aufbruch in die Neuzeit 1500-1650 (Handbuch der Geschichte Europas 5; UTB 2385), Stuttgart 2003, S. 68.
} 
erfolgreich beendete Reconquista, also die Rückeroberung Spaniens von den Mauren, die eigentlichen Voraussetzungen für das Ausgreifen in die Neue Welt. Diese stehen einerseits in ursächlichem Zusammenhang mit der im gleichen Zuge zunehmenden Zentralisierung und weiträumig erstarkenden Katholizität des Gebietes Kastilien-Aragón, und gründen sich andererseits insgesamt auf weit ältere Prozesse:

Bereits im Zuge des 13. und 14. Jahrhunderts kam es zur systematischen Eroberung des Mittelmeerraumes durch die Krone von Aragón und damit zur Etablierung eines ersten, spanischen', das heißt aragónesischen, Kolonialreiches. Zur gleichen Zeit tat sich insbesondere das Königreich Kastilien im Kampf um die Zurückdrängung der muslimischen Fremdherrscher, die noch bis ins 15. Jahrhundert weite Teile der südlichen Pyrenäenhalbinsel regierten, hervor. Mit der Vermählung der später so genannten ,Katholischen Könige,,52 Ferdinand II. von Aragón und Isabella I. von Kastilien, in der zweiten Hälfte des 15. Jahrhunderts kam es also nicht nur zur Verschmelzung zwei der einflussreichsten, sondern zugleich auch zweier grundsätzlich expansionswilliger Machtbereiche auf iberischem Boden. Ein Expansionsdrang, der mit der erfolgreich beendeten Reconquista zu einem gemeinsamen Höhepunkt geführt und den Blick über die Grenzen der eigenen Gebiete hinausgeleitet hatte. Das Fundament für einen zentralistischen Staat ${ }^{53}$ inklusive starkem Missionsierungsgedanken, das zugleich Ausgangspunkt und Ursprungsgebiet des hispanoamerikanischen Imperiums werden sollte, war damit gelegt.

Hierbei begünstigten sich wiederum mehrere, teils schlicht historisch zufällige Gegebenheiten gegenseitig: Erstens verbanden sich mit der genannten Personalunion zwei Mächte, die im Falle Aragóns auf Erfahrung in der Mittelmeerseefahrt und die dortige Koloniegründung und -herrschaft, im Falle Kastiliens auf die Eindrücke der (Rück-)Eroberung fremdbeherrschter Gebiete blicken konnten. Zweitens fällt in ebendiese Zeit die Suche eines Seeweges in das gold- und gewürzreiche Indien, als Alternative zum Landweg, der von den im Osten ebenfalls expandierenden Osmanen beherrscht wurde. In diesem Zusammenhang ist drittens die andauernde, aber offenbar befruchtende Konkurrenz mit dem benachbarten Portugal zu nennen, ${ }^{54}$ das bereits seit Mitte des 15. Jahrhunderts Erfolge in dem Bestreben, Afrika der Küste entlang zu umsegeln, vorweisen konnte. ${ }^{55}$ Als Folge daraus ergab sich viertens die überaus glückliche Fügung, dass der Genuese Christoph Columbus im Auftrag Ferdinands und Isabellas ebenfalls 1492 den Seeweg gen Westen einschlug und hier zufällig die Vorposten eines bis da

52 Die 1468 vermählten Thronprätendenten Ferdinand von Aragón und Isabella von Kastilien erhielten 1494 den Ehrentitel Los Reyes Catholicos - „Die Katholischen Könige“ - von Papst Alexander VI. verliehen als Folge der erfolgreichen Rückeroberung muslimischer Herrschaftsgebiete in die christliche Einflusssphäre. Vogler, Europas Aufbruch, S. 69.

53 Aufgrund des Ungleichgewichtes, das zwischen beiden Gebieten herrschte, da diese nur über die Ehegemeinschaft der beiden Souveräne verbunden waren, ihre Eigenständgkeit aber jeweils beibehielten, kam es zu einer umfassenden Um- und Neustrukturierung in beiden Herrschaftsbereichen, was den späteren Entwicklungen im Kontext der Expansion ebenfalls zuträglich war. Hierzu ausführlicher Vogler, Europas Aufbruch, S. 69-75.

54 J. H. Parry, The Spanish Seaborne Empire, London 1966, S. $39 \mathrm{ff}$.

55 Urs Bitterli (Hrsg.), Die Entdeckung und Eroberung der Welt. Dokumente und Berichte, Bd. 1, Amerika, Afrika (Beck'sche Sonderausgaben), München 1980, S. 18. 
hin unbekannten Kontinentes entdeckte, die er umgehend für seine Auftraggeber in Besitz nahm. ${ }^{56}$ Spaniens Weg zur Weltmacht war damit geebnet.

\section{Landnahme und Weltmachtstellung im 16. Jahrhundert}

Das teils eher historisch zufällige Zusammenspiel günstiger innerer und äußerer Faktoren auf der Pyrenäenhalbinsel hatte also noch im 15. Jahrhundert die nötigen Voraussetzungen für eine spanische Expansion geschaffen, die sich im 16. Jahrhundert beharrlich fortsetzte. So hatte das noch 1492 von Columbus eroberte Hispanola - heute Dominikanische Republik und Haiti - das „Tor zu neuen Kolonien"57 geöffnet. Die sukzessive Landnahme der neu entdeckten Gebiete folgte auf dem Fuße: Bis 1496 wurde die Karibik erobert, 1519 bis 1529 das Aztekenreich in Mexiko und Mittelamerika, 1531 bis 1534 das Inkareich von Quito, Peru und Chile und in den 1560er-Jahren folgten schließlich die Philippinen als westlichster kolonialer Besitz. Das heißt, weniger als ein Jahrhundert nach dem Ausgreifen auf die Neue Welt konnte Spanien also tatsächlich auf ein Weltreich blicken, das von den Niederlanden bis nach Süditalien und vom Mittelmeer über den Atlantik bis in den Indischen Ozean reichte. Also im wahrsten Sinne des Wortes auf ein Reich, in dem die Sonne sprichwörtlich niemals unterging. Dadurch avancierte Spanien noch im 16. Jahrhundert zum reichsten Land der damaligen Welt inklusive einer neu errungenen Vormachtposition im europäischen Mächtekanon und auf dem besten Wege zur Hegemonialmacht. ${ }^{58}$ Dass der Weg zu Spaniens Großmachtwerdung aber keineswegs unproblematisch war, wird dabei oft kaum berücksichtigt und äußert sich in wenigstens zweierlei Blickrichtungen, wie folgende Ausführungen veranschaulichen sollen.

\section{Der Blick auf Spanien}

Mit Blick auf Spanien gründet sich dessen Aufstieg vor allem auf den Umstand, dass die hegemoniefördernden Faktoren auch im 16. Jahrhundert nach wie vor im Gang befindliche Prozesse waren. So hatte das "katholische Königspaar" siertes Kernland als Grundlage für das spätere Spanien geschaffen, die Personalunion der beiden Gebiete manifestierte sich indessen nur in der Ehegemeinschaft der beiden Souveräne und drohte mit Isabellas Tod 1504, spätestens aber mit dem ihres Gatten 1516, zu zerfallen. Aus „einem dynastischen Zufall”60 heraus gelangte schließlich der

56 Reinhard Wendt, Seit 1492: Begegnung der Kulturen, in: Völker-Rasor, Anette, Frühe Neuzeit (Oldenbourg Geschichte Lehrbuch), München 201033, S. 69-86, hier S. 69 f.

57 Fradera, Moderner Kolonialismus, S. 47.

58 Ebd., S. 47 f.

59 Vogler, Europas Aufbruch, S. 78.

60 Ebd., S. 75; im Detail Alfred Kohler, ,Karl V., Kaiser", in: Neue Deutsche Biographie 11 (1977), S. 191-211, [http://www. deutsche-biographie.de/ppn1 18560093.html], eingesehen 21.6.2015 (Die,Neue Deutsche Biographie' wird im Folgenden unter der Sigle „NDB online" abgekürzt).

Aufgrund diverser Todesfälle oder anderer, eine Thronfolge verhindernder Umstände spielte Karl bereits früh eine Rolle „in den Kombinationen der dynastischen Erbfälle" (ebd.). Als Sohn des bereits früh verstorbenen Habsburgers Philipp des Schönen und der kastilisch-aragónesischen Prinzessin Johanna der Wahnsinnigen, die ihre Eltern aufgrund ihrer Geisteserkrankung nicht auf dem Thron beerben konnte, fiel die Herrschaft schließlich an ihren Sohn Karl. Kohler, NDB online. 
gemeinsame Enkel Karl auf den kastilisch-aragónesischen Thron. Als Carlos I. vereinte er erstmals die beiden Reichsteile inklusive der unteritalienischen Königreiche und des noch 1512 von Ferdinand annektierten Navarras ${ }^{61}$ in einer Person, weshalb er gemeinhin als der erste spanische König gilt.62 Als solcher hatte er allerdings keinen leichten Stand bei seinen neuen Untertanen: Der im habsburgischen Burgund ohne seine Eltern aufgewachsene Thronprätendent sprach kaum ein Wort Spanisch und war mit den Strukturen vor Ort nicht vertraut. Probleme, die sich noch über Jahre hinziehen sollten. ${ }^{63}$

Dennoch hatte Karl "eine ganze Epoche der frühen neuzeitlichen Geschichte Europas nachhaltig geprägt."64 Als Erbe der habsburgischen Besitzungen seines Großvaters Maximilian I. und aufgrund seiner Wahl zum römisch-deutschen Kaiser 1519 - dadurch besser bekannt als Karl V. - herrschte der spanische König über weitläufige inner- und außereuropäische Besitzungen, während die nach wie vor andauernde Konkurrenz mit Portugal ${ }^{65}$ durch die Heirat mit der portugiesischen Infantin Isabella 1526 vorerst abgemildert werden konnte. Das erklärte politische Ziel Karls I.N. war indes, „dem spanischhabsburgischen Imperium die Hegemonie zu sichern".66 Wo Bernecker im Hinblick auf die spanische Conquista, also die Eroberung Amerikas, aber von einer "zielorientierten spanischen Politik" ${ }^{\prime 67}$ spricht, meint Fradera wiederum „[d]er spanischen kolonialen Ausdehnung lag nie ein fester Plan zugrunde","68 was der Autor wie folgt weiter ausführt:

„Die Eroberung erfolgte hauptsächlich durch die huestes, kleine bewaffnete Banden, die von Kapitalisten in Iberien finanziert und von der keineswegs illusorischen Aussicht auf schnellen Reichtum - oder wenigstens Herrschaft über die Örtliche Bevölkerung und Hoffnung auf künftigen Reichtum - angelockt wurden. [...] d.h. königliche, zivile und kirchliche [Landnehmer, Anm.] - folgten erst später im Zuge der Kolonisierung." ${ }^{\prime 69}$

Vorrangige Intention der Conquista war also die aussichtsreiche Ressourcenausschlachtung der neu erschlossenen und noch zu entdeckenden Gebiete in Übersee.

61 Bernecker, Spanische Geschichte, S. 18.

62 Die Neue Deutsche Biographie führt den spanisch-habsburgischen Souverän beispielsweise als „Karl V., Kaiser (Karl I. als König von Spanien)". Kohler, NDB online. Seine Vorgänger, etwa seine Großeltern Ferdinand und Isabella, waren im Gegensatz dazu noch keine spanischen Könige, sondern mehr oder minder eigenständige Herrscher über ihre jeweiligen Geburtsterritorien, die in Personalunion vereint wurden.

63 Vogler, Europas Aufbruch, S. 74 ff.; Kohler, NDB online.

64 Kohler, NDB online.

65 Während die Portugiesen seit dem 15. Jahrhundert nach und nach den afrikanischen Kontinent auf der Suche eines Seeweges nach Indien umsegelten, brachen die Spanier gen Westen auf, wo sie schließlich auf den als solchen noch unerkannten amerikanischen Kontinent stießen. Beide Mächte hatten sich dabei noch im Verlaufe des Jahrhunderts „ihre Besitzrechte vom Papst bestätigen lassen“, was allerdings nicht verhinderte, dass die Neue Welt weitere Entdeckungsfahrer anzog. So stießen kurz nach Columbus auch die Portugiesen an die Ostküste Südamerikas, was schließlich „durch den gemeinsam ausgehandelten Staatsvertrag von Tordesillas“ 1494 zur Aufteilung der Welt in zwei Interessenssphären - eine spanische und eine portugiesische - führte. Ein Grund, weshalb Brasilien bis heute der einzige südamerikanische Staat ist, in dem Portugiesisch anstelle von Spanisch die vorrangige Amtssprache ist. Bitterli, Entdeckung der Welt, S. 18.

66 Vogler, Europas Aufbruch, S. 75 f.; Bernecker, Spanische Geschichte, S. $18 \mathrm{ff}$.

67 Bernecker, Spanische Geschichte, S. 22

68 Fradera, Moderner Kolonialismus, S. 48

69 Ebd. 
Dass die Organisation der Conquista dabei nur allzu bald dem direkten Einflussbereich der kastilisch-aragónesischen Krone oblag, rührte wohl nicht zuletzt aus den teils gegenläufigen Verpflichtungen der spanischen beziehungsweise römisch-deutschen Regierungswürde: So stand auf der einen Seite die „wachsende Finanzlast der kaiserlichen Reichspolitik, auf der anderen das Edelmetallpotential des amerikanischen Kolonialreichs.“70 Das heißt, die Finanzierung der "politischen und militärischen Unternehmungen des Kaisers und später seines Sohnes Philipp [II. von Spanien, Anm.]"11 wurde seit den 1540er-Jahren zusehends über Spanien und hier über die spanischen Überseekolonien abgedeckt. ${ }^{72}$

\section{Die Landnahme}

Die Kolonisierung selbst war dabei unter etwa gleichartig gewichteten ökonomischmachtpolitischen wie missionarisch-zivilisatorischen Zielsetzungen wesentlich an die drei Hauptakteure Krone, Kirche und Konquistadoren beziehungsweise Kolonisten geknüpft. ${ }^{73}$ Wobei gerade die Conquistadores, die,Eroberer', wesentlich für die frühe Phase der erfolgreichen Landnahme waren. So hatte die Mentalität der Zeit - eine Mischung aus noch lebendiger Ritterromantik, Abenteuerlust, Wagemut und der Aussicht auf Verdienst, Ruhm und Ehre in den neuentdeckten Ländern ${ }^{74}$ - bereits seit den Entdeckungsfahrten des Columbus eine immer größer werdende spanische Bevölkerung in die Neue Welt gelockt. Diese ließ sich vor allem auf Hispanola nieder, „wo die bedenkenlose Ausbeutung der einheimischen Bevölkerung schnell zu deren Auslöschung führte". ${ }^{\prime 5}$ Ein trauriger Umstand, der sich auf dem Festland fortsetzen sollte.

Dennoch folgte von dort aus zusehends die Erkundung der Küstengebiete Mittel- und Südamerikas, wobei etwa 1513 Juan Ponce de León oder 1517 auch Francisco Hernández de Córdoba erstmals mit den mesoamerikanischen Hockulturen im Raum Yucatán in Berührung kamen. Der vielleicht bekannteste Conquistador, der als erster tiefer in das als goldreich geltende Landesinnere des neuen Kontinentes vordrang, war schließlich Hernán Cortéz. Durch ein Bündnis mit mehreren, in Oppsition zur aztekischen Oberherrschaft - seinerzeit mit dem in unseren Breiten vielleicht ebenfalls bekanntesten indigenen Herrscher Moctezuma ${ }^{76}$ an der Macht - stehenden lokalen Stämmen und nach mehreren Angriffen gelang im Verlaufe der Jahre 1519 bis 1521 die Eroberung des Aztekenreiches. Die vollkommene Inbesitznahme des sich im mittel- und südame-

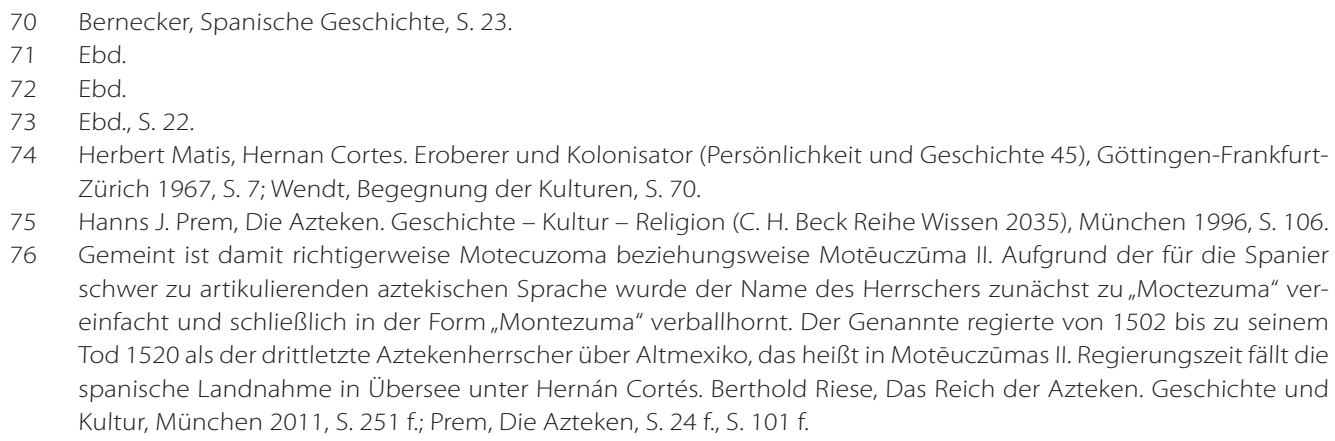
schwer zu artikulierenden aztekischen Sprache wurde der Name des Herrschers zunächst zu "Moctezuma“ vereinfacht und schließlich in der Form "Montezuma” verballhornt. Der Genannte regierte von 1502 bis zu seinem Tod 1520 als der drittletzte Aztekenherrscher über Altmexiko, das heißt in Motēuczūmas II. Regierungszeit fällt die spanische Landnahme in Übersee unter Hernán Cortés. Berthold Riese, Das Reich der Azteken. Geschichte und Kultur, München 2011, S. 251 f.; Prem, Die Azteken, S. 24 f., S. 101 f. 
rikanischen Raum ausdehnenden aztekischen Herrschaftsbereiches setzte sich zwar noch bis circa 1530 fort, dennoch bewerten Osterhammel/Jansen Cortés' Eroberung als große Ausnahme: „Koloniale Herrschaft war so gut wie nie durch blitzartige Überfälle auf vollkommen unvorbereitete Opfer zustandegekommen".77 Das aztekische Großreich war Hanns J. Prem zufolge mit Cortés Eroberung jedenfalls erloschen und erhielt - mit dem verantwortlichen Conquistador als Vizekönig an der Spitze, der direkt Karl V. unterstellt war - den Namen,Neuspanien'?8

Mit den nun spanischen Landbeherrschern hielt auch das bereits in der Karibik etablierte System der encomiendas Einzug, also eine Art Feudalsystem zum Zwecke der Landerschließung und -bewirtschaftung. Dieses sprach dem encomendero, dem Landbesitzer, das Recht zu, Tribut und Arbeitsleistung von der eingeborenen Bevölkerung zu fordern, und barg die Pflicht, sich im Gegenzug um das Wohlergehen der Untergebenen zu sorgen und ihnen die spanisch-christliche Lebensweise näher zu bringen. Ziel war also gleichermaßen die Gewinnung von Land, Ressourcen und neuen Christenmenschen für die spanische Krone. Die Realität war allerdings von der gewaltvollen Inbesitznahme eigentlich besiedelten Landes, der Ausbeutung indianischer Arbeitskraft und letztlich der Ausrottung der indigenen Bevölkerung begleitet, ${ }^{79}$ wie der Blick auf die Situation in Übersee verdeutlicht.

\section{Der Blick nach Übersee}

Die geschildete, vorrangig ökonomisch motivierte Ausbeutung von Land und Leuten auf der Suche nach schnellem Reichtum in Kombination mit dem Fehlen entsprechender Kontroll- und Verwaltungsinstanzen, schlechten Arbeitsbedingungen für die indigene Bevölkerung und dem Einschleppen heimischer Krankheiten, denen die Indios kaum etwas entgegenzusetzen hatten, mündete bald nach dem Ankommen der Europäer in einer demographischen Katastrophe: In weniger als achtzig Jahren nach Ankunft der Europäer kam es zur regelrechten Entvölkerung Mittel- und Südamerikas. Umstände, die bereits unter Zeitgenossen für Kritik sorgten und die ersten,Völkerrechtler' wie etwa den Dominikanermönch Bartolomé de las Casas hervorbrachten. ${ }^{80}$ Dieser schildert in einem zeitgenössischen Bericht von 1552 Entsprechendes über die von ihm als „überaus milde, geduldig, friedfertig und ruhig, ohne Hang zu Zank und Unfriede, weder streitsüchtig noch neidisch, ohne Tücke und Haß und Rachsucht" ${ }^{\prime \prime 1}$ beschriebenen Indios:

„Über diese sanftmütigen, von ihrem Herrn und Schöpfer mit solcher Wesensart begabten Menschen kamen nun die Spanier, und zwar vom ersten Augenblick an, wo sie sie kennenlernten, wie grausame Wölfe, Tiger und Löwen, die man tagelang hat hungern lassen. Sie haben in diesen vierzig Jahren bis zum

77 Osterhammel/Jansen, Kolonialismus, S. 45

78 Prem, Die Azteken, S. 106-115; Cipolla, Spanisches Silber, S. 11 ff.; Matis, Hernan Cortes, S. 9-16.

79 Prem, Die Azteken, S. 118 ff.; Fradera, Moderner Kolonialismus, S. 48.

80 Fradera, Moderner Kolonialismus, S. $48 \mathrm{ff}$.

81 Bartolomé de las Casas, Die Greueltaten der Spanier (Auszug aus Brevissima Relación), in: Bitterli (Hrsg.), Entdeckung der Welt, S. 52. 
heutigen Tage nichts anderes getan und tun auch heutzutage nichts anderes als zerreißen, töten, ängstigen, quälen, foltern und vernichten, auf jede nur denkbare, nie gehörte, nie gesehene, nie erlebte Art äußerster Grausamkeit [...]. Und das alles in solchem Maße, daß auf der Insel Española von drei Millionen Seelen, die zu unserer Zeit dort gelebt haben, heute keine 200 mehr da sind. Die Insel Kuba hat eine Längenausdehnung, die etwa der Entfernung von Valladolid nach Rom entspricht; sie ist heute fast entvölkert. [...] Das ausgedehnte Festland haben unsere spanischen Landsleute durch ihre Greuel und gottlosen Taten entvölkert und verheert. Mehr als zehn Königreiche, größer als ganz Spanien, Portugal und Aragón eingeschlossen, einst von Menschen mit hoher Kultur bewohnt, sind heute entvölkert;"

Wenngleich derartige Berichte und Appelle die vorherrschende Situation nicht zu ändern vermochten, „sind sie doch bedeutungsvoll als Zeugnisse einer Gewissensgründung, wie sie die europäische Expansion nach Übersee bis in unser Jahrhundert begleitet hat",83 resümiert im Zusammenhang etwa Urs Bitterli. Zwar folgte noch vor Mitte des 16. Jahrhunderts die Ausarbeitung von Gesetzen, die den Umgang mit der Ureinwohnerschaft regeln sollten, sowie die Einrichtung eines Verwaltungsapparates, bestehend aus politischen, gerichtlichen und städtischen Institutionen, dies gereichte den indigenen Einwohnern aber nicht zwangsläufig zum Besseren. Die enorme Dezimierung der ortsansässigen Bevölkerung im Laufe des 16. Jahrhunderts markierte "das Ende der präkolumbianischen Kulturen"," ,ermöglichte' allerdings - ausschließlich für die Spanier von Vorteil - im gleichen Zuge das Entstehen einer neuen, widerstandsfähigen kolonialen Gesellschaft. Letzteres auf Grundlage der „nunmehr übereinstimmenden Ziele des imperialen Staates mit denen der frühen Gruppen privater Kolonisten [...] und [...] der Fähigkeit der Einheimischen [...] zu widerstehen und sich den Forderungen ihrer neuen Herren anzupassen." ${ }^{185}$

Mit Blick auf die indigenen Reiche jener Zeit, beispielsweise das Aztekenreich, ist also festzuhalten, dass diese den Europäern völlig fremden Kulturen just zu dem Zeitpunkt „in das Licht der europäischen Aufmerksamkeit [... rückten ...], als durch die spanische Eroberung ihre eigenständige Geschichte zu einem abrupten Ende kam." D6 Die knapp fünfzig Jahre von der endgültigen Rückeroberung Iberiens von den Mauren im Jahre 1492 zur eigenmächtigen Eroberung fremder Gebiete in der Neuen Welt unter Inkaufnahme der Auslöschung ganzer Ethnien bis zur Mitte des 16. Jahrhunderts hatte Spanien also den Weg zur Großmacht bereitet. Doch während der frühneuzeitliche Kolonialismus für die Spanier Reichtum, Ruhm und den Status einer Weltmacht bedeutete, waren die Indios mit dem Untergang ihrer angestammten Welt konfrontiert.

82 De las Casas, Greueltaten der Spanier, S. 52 f.

83 Bitterli, Entdeckung der Welt, S. 19.

84 Fradera, Moderner Kolonialismus, S. 50

85 Ebd., S. 50; ebd. S. $49 \mathrm{ff}$

86 Prem, Die Azteken, S. 7. 
Nachdem im Verlaufe dieser Arbeit zum einen recht deutlich wurde, dass Kolonialismus ein überaus weit ausgreifendes, vielgestaltiges und nur schwer zu definierendes Phänomen ist und zum anderen das Werden des spanischen Kolonialreiches - als ein Beispiel von Kolonialismus - dargelegt wurde, stellt sich abschließend noch die Frage nach dem Wesen des frühneuzeitlichen spanischen Imperiums. Konkret: Wie war das spanische Kolonialreich beschaffen und wie ist der spanische Kolonialismus zu bewerten?

Dass der spanische Kolonialismus womöglich einen Sonderfall oder zumindest etwas Eigenes innerhalb der Kolonialismusforschung darstellt, implizieren beispielsweise Josep Fradera oder Osterhammel/Jansen. Wo Ersterer wiederholt etwa vom "Spanischen Modell" ${ }^{47}$ spricht und sogar die Frage stellt: "War das spanische Imperium ,kolonialistisch'?",8 klassifizieren Letztgenannte mit der Beherrschungs-, der Stützpunkt- sowie der Siedlungskolonie ${ }^{89}$ drei Ausformungen. Bei der Beherrschungskolonie - meist eine Folge militärischer Eroberung zum Zwecke wirtschaftlicher Ausbeutung und Prestigesteigerung, wobei die Landnahme durch eine relativ kleine Anzahl von "Zivilbürokraten, Soldaten [und] Geschäftsleuten"90 erfolgt - ist die Rede von der "Variante Spanisch-Amerika".91 Also einer spezifischen Form des Kolonialismus, bei der „europäische Einwanderung [...] zu städtischer Mischgesellschaft mit dominierender kreolischer ${ }^{92}$ Minderheit" ${ }^{193}$ führt, die es demnach nur im spanisch-amerikanischen Einflussbereich gegeben hat. Dass dem tatsächlich so war, also dass im hispanoamerikanischen Raum tatsächlich eine Mischgesellschaft entstanden ist, hat sich durchaus im Verlaufe der hier vorliegenden Untersuchungen bestätigt. So war der Aufstieg der spanischen Kolonien offenbar wesentlich mit ebendieser Entwicklung verbunden und erst die Entstehung einer derartigen neuen Gesellschaft hat das spanische Kolonialreich schließlich zu seiner Blüte im 17. beziehungsweise 18. Jahrhundert geführt.

$\mathrm{Ob}$ dies allein reicht, um vom spanischen Kolonialismus als Sonderfall sprechen zu können, geschweige denn diesen in seinem Wesen komplett zu erfassen, sei allerdings dahingestellt. An anderer Stelle und mit Blick auf die modernen Imperien verweisen Osterhammel/Jansen nämlich auch darauf, dass selbige in keiner Zeit "administrativ homogen"94 waren. Wenngleich die Autoren den Schwerpunkt hier verstärkt auf das 18. bis 20. Jahrhundert legen, lässt sich diese Feststellung doch auch auf die Kolonialreiche der Frühen Neuzeit anwenden. So meint etwa Reinhard Wendt mit Bezug auf die frühneuzeitlichen Kolonialreiche Spanien und Portugal: „Strukturell unterschieden

87 Fradera, Moderner Kolonialismus, S. 53, $66 \mathrm{f}$.

88 Ebd., S. 51.

89 Zur detaillierten Klassifikation siehe Osterhammel/Jansen, Kolonialismus, S. 16-18.

90 Osterhammel/Jansen, Kolonialismus, S. 17.

91 Ebd

92 Das Adjektiv „kreolisch", abgeleitet von „Kreole“ verweist auf die Nachkommen weißer romanischer Einwanderer in Süd- und Mittelamerika beziehungsweise auf die Nachkommen schwarzer Sklaven in Brasilien. Kreole, in: Duden online, [http://www.duden.de/rechtschreibung/Kreole_Nachkomme_Einwanderer], eingesehen 12.6.2015. 
sich beide Imperien [...] grundlegend. Verantwortlich dafür waren nicht divergierende Interessen der jeweiligen Mutterländer, sondern die Bedingungen vor Ort." ${ }^{\prime 95}$ Das heißt also, welche Form Kolonialimus im Einzelnen annimmt, hängt von verschiedenen Faktoren ab und muss demnach individuell an die jeweiligen Gegebenheiten der kolonialiserten Gebiete angepasst werden. Für eine eindeutige(re) Verortung des spanischen Kolonialismus müsste hier freilich ein Vergleich mit anderen Kolonialmächten der Zeit angestellt werden, was den Rahmen dieser Arbeit bei weitem sprengen würde. Deshalb sei an dieser Stelle auf entsprechende Einzeldarstellungen verwiesen, wie sie beispielsweise Robert Aldrichs Sammelband "Ein Platz an der Sonne" bietet.

Für das spanische Kolonialreich sei jedenfalls das Folgende festgehalten: Die Frage nach einem Sonderfall in Bezug auf das spanische Imperium rührt vermutlich daher, dass es offiziell nie Kolonien besaß, da bis ins 18. Jahrhundert entsprechendes Vokabular nicht verwendet wurde. ${ }^{96}$ So war nie von colonia, sondern offiziell von den reynos de las Indias, also den, indischen Königreichen' die Rede, bei denen es sich staatsrechtlich um „selbstständige Teilreiche der Krone Kastilien, nicht um Untertanenländer des Landes Kastilien"97 gehandelt hatte. Eine juristische Haarspalterei, die kaum über die „Unterwerfung und Entmündigung der Eingeborenen"98 noch über deren „tendenzielle[...] wirtschaftliche[...] Abhängigkeit von Europa"99 hinwegzutäuschen vermag. ${ }^{100}$ Oder anders ausgedrückt: „[S]ozioökonomisch handelt es sich unzweifelhaft um Kolonien und dieser Sachverhalt findet durchaus auch Niederschlag in der Herrschaftsorganisation."101

Insofern ist der spanische Kolonialismus bei all seinem Eifer zur Erschließung neuer Edelmetallvorkommen, Missionierung mit päpstlichem Wohlwollen und dem allgemeinen Weltmachtstreben von umfassender Dezentralität gekennzeichnet. ${ }^{102}$ Dies, weil der spanischen Expansion ursprünglich kein fester Plan zugrunde lag, wenngleich die spätere Organisation des Weltreiches anderes vermuten lässt. Die Regierung unterstand jedenfalls über lange Zeit hinweg - das heißt bis in das 18. Jahrhundert hinein und trotz der augenscheinlichen Eigenverwaltung der, indischen Königreiche' direkt der spanischen Krone im fernen europäischen Mutterland. Gerade deshalb ist in höchstem Maße bemerkenswert, dass das hispano-amerikanische Imperium, etwa nach Fraderas Bewertung, letztlich trotzdem eine „planvoll durchdachte, nach einheitlichen Aspekten bis ins Einzelne geregelte staatliche Schöpfung darstellt, wie sie sonst nirgends zur Durchführung gelangte, und vier Jahrhunderte die Herrschaft sicherte."103 Also durchaus ein Sondermodell, dass sich erst mit dem Einmarsch Napoleons im europäischen Mutterland und der damit einhergehenden größeren politischen Liberalität für die Kolonien im 19. Jahrhundert aufzulockern begann, was allerdings gleichbedeu-

\footnotetext{
95 Wendt, Begegnung der Kulturen, S. 72.

96 Hierzu auch Anmerkung 15.

97 Reinhard, Die Neue Welt, S. 69.

98 Ebd.

99 Ebd

100 Ebd., S. 69 f.; Fradera, Moderner Kolonialismus, S. 53.

101 Reinhard, Die Neue Welt, S. 69.

102 Fradera, Moderner Kolonialismus, S. 48

103 Ebd., S. 67
} 
tend mit dem Niedergang des spanischen Imperiums war. Denn: „Mit der Lockerung seiner Herrschaft über Amerika hörte Spanien auf, eine den Atlantik überspannende Nation zu sein, [...]."104

\section{Schluss}

Beschäftigt man sich mit frühneuzeitlichen Kolonialismen, begibt man sich gleichermaßen in ein höchst interessantes aber auch höchst komplexes Feld. So ist allein der Begriff „Kolonialismus" nur schwer definierbar, ähnlich der (wort-)verwandten Termini, wie "Kolonisation" oder auch „Imperialismus" und „Expansion”. Dennoch lässt sich im Allgemeinen festhalten, dass kolonialistische Herrschaft durchaus begründet zumeist negativ konnotiert ist, da sie in der Regel mit der Expansion einer Macht über "ihren angestammten Lebensraum hinaus" einhergeht, wie etwa Osterhammel/Jansen so treffend formulierten. Hinzu kommt oft noch ein gewisses Weltmachtstreben, wie es auch dem spanischen Kolonialreich spätestens seit dem 16. Jahrhundert eindeutig zugrunde lag.

Als exemplarisches Beispiel dieses vielgestaltigen Phänomens zeichnet sich das spanische Kolonialreich, das von der Entdeckung Amerikas durch Columbus 1492 bis zur Unabhängigkeit der letzten verbliebenen Kolonien 1898 knapp vier Jahrhunderte überdauerte, durch Dezentralität und mitunter auch enorme Gewalt aus. Ersteres, da die Regierung lange Zeit, das heißt bis ins 18. Jahrhundert, direkt der Krone im räumlich weit entfernten Mutterland unterstand, letzteres verdeutlicht sich nicht zuletzt an der bedenkenlosen Ausbeutung von Land und Leuten, die gerade in den Anfängen der spanischen Expansion gen Übersee eine enorme Dezimierung der indigenen Bevölkerung zur Folge hatte.

Gerade diese Anfänge des spanischen Ausgreifens auf die Welt waren dabei Hauptinteressenspunkt der hier vorliegenden Untersuchung. Bereits seit der Antike war die Pyrenäenhalbinsel immer wieder kolonialisiertes Gebiet, etwa durch die Phönizier, die an den Küsten Handelsstützpunkte errichteten, oder durch die Römer, die weiter ins Landesinnere vordrangen. Unter dem Eindruck der seit dem achten nachchristlichen Jahrhundert auf der Halbinsel expandierenden islamischen Herrscher begannen sich die ortsansässigen Ethnien aber scheinbar zu emanzipieren, sodass es seit dem 13. Jahrhundert zur Etablierung der so genannten christlichen,Fünf Reiche' kam. Aus diesem noch im 15. Jahrhundert bestehenden Konglomerat kleiner und mittlerer Königreiche und Fürstentümer auf der Iberischen Halbinsel entstanden schließlich zwei der ersten Kolonialmächte der Frühen Neuzeit: Portugal und Spanien.

Im iberischen Raum jener Zeit scheinen also in der Tat ganz bestimmte Voraussetzungen und Entwicklungstendenzen in absolut begünstigender Weise für eine Überseeexpansion der dort ansässigen Mächte zusammengeflossen zu sein: Mit der Personalunion von Aragón und Kastilien fanden 1469 - neben Portugal - die zwei mächtigsten und einflussreichsten iberischen Mächte zusammen, die sich durch ihren jeweils ei-

104 Fradera, Moderner Kolonialismus, S. 66. 
genen Expansionswillen auszeichneten und mit der Formierung eines zentralisierten Staates letztlich die Grundlage für ein spanisches Großreich schufen. Die anhaltende Konkurrenz mit Portugal auf der Suche nach einem Seeweg gen Indien, der die Portugiesen um Afrika herum geführt hatte und Kastilien-Aragón nur noch die Alternative gen Westen offen ließ, in Kombination mit Columbus' Zufallsentdeckung - Amerika tat das Übrige zur Gründung eines Weltreiches. Denn neben all diesen teils historisch zufällig zusammenspielenden Faktoren, die eine spanische Expansion begünstigten, waren es letztlich die Kolonien im neu entdeckten Mittel- und Südamerika, die Spaniens Hegemonialstellung nicht nur begründeten, sondern langfristig stützten. Unter dem Eindruck eines grundsätzlichen Expansionsstrebens der Zeit, gepaart mit den Resten mittelalterlicher Ritterromantik, Abenteuerlust und den ganz realen Versprechungen auf persönlichen Besitz und Reichtum, fanden sich seit der Entdeckung des Columbus 1492 immer mehr Europäer in der Neuen Welt ein. So wurde bis 1496 die Karibik in Besitz genommen, 1519 bis 1529 folgte das mesoamerikanische Aztekenreich, bis Mitte der 1540er-Jahre das Inkareich und in den 1560ern schließlich die Philippinen. Bereits zum Ende des 16. Jahrhunderts konnte Spanien also tatsächlich auf ein Weltreich blicken, das durch entsprechend straffe Organisation und Verwaltung bis ins 19. Jahrhundert Bestand hatte.

Die Erschließung dieser seinerzeit noch völlig unbekannten Gebiete war wesentlich an die so genannten Conquistadoren gebunden. Glücksritter auf der Suche nach Ruhm und Reichtum in der Neuen Welt, die seit Beginn des 16. Jahrhunderts zunächst die Küstengebiete Südamerikas erkundet hatten und spätestens seit den 1530ern mit Hernán Cortéz tiefer in das als goldreich geltende Landesinnere eines unerforschten Kontinentes vordrangen. Der angebliche Goldreichtum der indigenen Hochkulturen und die fraglos faszinierenden Eindrücke dieser Fremde trugen wohl mit zu dem Wunsch bei, diese Gebiete erobern und unter eigene Herrschaft bringen zu wollen. Ein Ansinnen, das für die Europäer, allen voran die Spanier, vor allem durch den Einsatz der den Indios unbekannten Feuerwaffen von Erfolg gekrönt war. Auch wenn die Landnahme nicht immer von der absichtlichen Vernichtung der ansässigen Ureinwohnerschaft bestimmt war, führten vor allem die eingeschleppten Krankheiten sowie die bedenkenlose Ausbeutung der indigenen Arbeitskräfte noch im 16. Jahrhundert zur regelrechten Entvölkerung Mittel- und Südamerikas, was auch Eingang in zeitgenössische Quellen fand.

Der Aufstieg Spaniens - das zu Beginn des spanischen Kolonialismus unter diesem Namen eigentlich noch gar nicht existierte - am Übergang vom 15. zum 16. Jahrhundert ist also gleichbedeutend mit dem Übergang von der Reconquista, also der Rückeroberung der eigenen Landstriche in Europa, zur Conquista, der Eroberung der Neuen Welt in Übersee. Die Entdeckung und Landnahme der neu entdeckten Gebiete jenseits des Atlantiks war dabei Grundlage und Stütze der neuen Hegemonialmacht Spanien, die bis ins 17. Jahrhundert tonangebend im europäischen Mächtekanon war. Zugleich hatten die Entdeckungsfahrten des Columbus auch für andere europäische Mächte 
ein Tor zu neuen Welten und Möglichkeiten geöffnet, sodass im Kontext der europäischen Expansion die spanische immer mitgedacht werden muss.

Insofern haben sich die eingangs aufgestellten Hypothesen also durchaus bestätigt, auch was den Aufstieg und Fall ganzer Reiche im Zuge des frühneuzeitlichen Kolonialismus anbelangt. So ging die Großmachtwerdung Spaniens ganz klar mit dem zeitgleichen Niedergang der präkolumbianischen Kulturen Mittel- und Südamerikas konform, wie etwa am Beispiel des Hernán Cortés und des Aztekenreiches unter Moctezuma angedeutet. Der Umfang der vorliegenden Arbeit hat es nicht gestattet, hier näher ins Detail zu gehen, wobei ein exemplarisches Beispiel - ausgerechnet der von Osterhammel/Jansen als Sonderfall deklarierte Eroberungszug des Cortés - die Situation vermutlich auch nicht ausreichend beleuchtet hätte. Ebenso wie in Hinblick auf eine eindeutige Bewertung des spanischen Kolonialismus wäre auch in Bezug auf die indigenen Reiche zur Zeit der europäischen Übersee-Expansion ein Vergleich mehrerer Beispiele gefragt.

\section{Literatur}

Aldrich, Robert, Einführung, in: Ders. (Hrsg.), Ein Platz an der Sonne. Die Geschichte der Kolonialreiche, Stuttgart 2008, S. 6-26.

Bennassar, Bartolomé/Vincent, Bernard, Spanien. 16. und 17. Jahrhundert. Das Goldene Zeitalter, Stuttgart 1999.

Bernecker, Walther L., Spanische Geschichte. Vom 15. Jahrhundert bis zur Gegenwart (C. H. Beck Reihe Wissen 2111), München 1999.

Bitterli, Urs (Hrsg.), Die Entdeckung und Eroberung der Welt. Dokumente und Berichte, Bd. 1, Amerika, Afrika (Beck'sche Sonderausgaben), München 1980.

Bley, Helmut/Faroqhi, Suraiya/König, Hans-Joachim/Nolte, Hans-Heinrich/Rinke, Stefan, Enzyklopädie der Neuzeit, online [http://referenceworks.brillonline.com/entries/ enzyklopaedie-der-neuzeit/expansionen-a1004000], eingesehen 12.4.2015.

Bley, Helmut, Kolonialismus, in: Bley, Helmut/König, Hans-Joachim/Ahuja, Ravi/Nolte, Hans-Heinrich, Enzyklopädie der Neuzeit, [http://referenceworks.brillonline.com/entries/enzyklopaedie-der-neuzeit/kolonialismus-a2159000], eingesehen 12.4.2015.

Cipolla, Carlo M., Die Odyssee des spanischen Silbers. Conquistadoren, Piraten, Kaufleute, Berlin 1998.

Duden online, [http://www.duden.de/rechtschreibung/Kolonie], eingesehen 14.4.2015.

Expansion, in: Friedrich Kluge (Hrsg.), Etymologisches Wörterbuch der deutschen Sprache, Berlin-New York $2011^{25}$, S. 267.

Fisch, Jörg, Imperialismus, I. Einleitung - II. 3. Neuzeit, in: Otto Brunner/Werner Conze/Reinhart Koselleck (Hrsg.), Geschichtliche Grundbegriffe. Historisches Lexikon zur politisch-sozialen Sprache in Deutschland, Band 3 H-ME, Stuttgart 1982, S. 171-175. 
Fradera, Josep, Spanien - der Ursprung des modernen Kolonialismus, in: Robert Aldrich (Hrsg.), Ein Platz an der Sonne. Die Geschichte der Kolonialreiche, Stuttgart 2008, S. 44-68.

Herbers, Klaus, Geschichte Spaniens im Mittelalter. Vom Westgotenreich bis zum Ende des 15. Jahrhunderts, Stuttgart 2006.

Kluge, Friedrich, Etymologisches Wörterbuch der deutschen Sprache, Berlin-New York $2011^{25}$.

Kohler, Alfred, „Karl V., Kaiser“, in: Neue Deutsche Biographie 11 (1977), S. 191-211, [http://www.deutsche-biographie.de/ppn1 18560093.html], eingesehen 12.7.2015.

López Marichal, Juan, Rezension zu: El imperio hispánico y los cinco reinos, in: Nueva Revista de Filología Hispánica, 5 (1951), Nr. 3, S. 338-340, [http://www.jstor.org/stable/40296709], eingesehen 7.7.2015.

Matis, Herbert, Hernan Cortes. Eroberer und Kolonisator (Persönlichkeit und Geschichte 45), Göttingen-Frankfurt-Zürich 1967.

Osterhammel, Jürgen/Jansen, Jan C., Kolonialismus. Geschichte, Formen, Folgen (C. H. Beck Reihe Wissen), München $2012^{7}$.

Parry, J. H., The Spanish Seaborne Empire, London 1966.

Prem, Hanns J., Die Azteken. Geschichte - Kultur - Religion (C. H. Beck Reihe Wissen 2035), München 1996.

Reinhard, Wolfgang, Geschichte der europäischen Expansion, Bd. 1, Die Alte Welt bis 1818, Stuttgart 1983.

Ders., Geschichte der europäschen Expansion, Bd. 2, Die Neue Welt, Stuttgart-BerlinKöln-Mainz 1985.

Riese, Berthold, Das Reich der Azteken. Geschichte und Kultur, München 2011.

Schmitt, Eberhard, Vorwort, in: Die mittelalterlichen Ursprünge der europäischen Expansion (Dokumente zur Geschichte der europäischen Expansion 1), München 1986, S. V-VIII.

Vogler, Günter, Europas Aufbruch in die Neuzeit 1500-1650 (Handbuch der Geschichte Europas 5; UTB 2385), Stuttgart 2003.

Weidert, Michael, Rezension zu: Ein Platz an der Sonne, in: Sehepunkte. Rezensionsjournal für die Geschichtswissenschaften, 8 (2008), Nr. 11, [http://www.sehepunkte.de/ 2008/11/14373.html], eingesehen 16.6.2015.

Wendt, Reinhard, Seit 1492: Begegnung der Kulturen, in: Anette Völker-Rasor (Hrsg.), Frühe Neuzeit (Oldenbourg Geschichte Lehrbuch), München 2010³, S. 69-86. 


\section{Quelle}

Bartolomé de las Casas, Die Greueltaten der Spanier (Auszug aus Brevissima Relación), in: Urs Bitterli (Hrsg.), Die Entdeckung und Eroberung der Welt. Dokumente und Berichte, Bd. 1, Amerika, Afrika (Beck'sche Sonderausgaben), München 1980, S. 51-53.

\section{Abbildungsverzeichnis}

Abbildung 1: Herbers, Klaus, Geschichte Spaniens im Mittelalter. Vom Westgotenreich bis zum Ende des 15. Jahrhunderts, Stuttgart 2006, S. 181.

Abbildung 2: Herbers, Klaus, Geschichte Spaniens im Mittelalter. Vom Westgotenreich bis zum Ende des 15. Jahrhunderts, Stuttgart 2006, S. 187.

Lisa-Marie Gabriel ist Studentin der Geschichtswissenschaften sowie des Lehramtsstudiums Deutsch/Geschichte, Sozialkunde und Politische Bildung im 8. Semester an der Universität Innsbruck. lisa-marie.gabriel@student.uibk.ac.at

\section{Zitation dieses Beitrages}

Lisa-Marie Gabriel, Neuzeitliche Kolonialismen: Das Kolonialreich Spanien. Der Aufstieg des spanischen Kolonialreiches an der Wende zur Frühen Neuzeit, in: historia.scribere 8 (2016), S. 161-184, [http://historia.scribere.at], 2015-2016, eingesehen 14.6.2016 (=aktuelles Datum).

Creative Commons Licences 3.0 Österreich unter Wahrung der Urheberrechte der Autorlnnen. 
